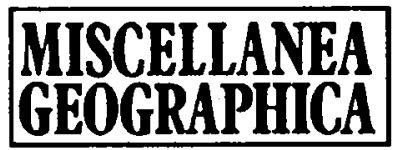

WARSZAWA 1996 Vol. 7

Jan Goleń, Wiesław Ostrowski

\title{
REMARKS ON THE DASYMETRIC METHOD
}

The persons dealing with the methodology of cartography are as a rule aware of existence of the presentation method called dasymetric method. This particular method can be found in the handbooks, especially those elaborated within the English speaking community. While such cartographic forms of presentation of quantitative data as the choropleth map, the dot map, or the isoline map have been widely, frequently and from many a point of view analysed and described, the dasymetric method has been the subject of relatively few and only superficial analyses. Thus, a closer look at this method might be of some use.

Opinions as to the place taken by the dasymetric presentation among the cartographic methods are quite diverse. Some distinguish it as one of the forms of quantitative presentation, side by side with the choropleth map, graduated symbol map, the isoline map and the dot map (Ratajski, 1973). Some other, like, for instance, A.H. Robinson and associates in their Elements of Cartography $(1978,1985)$ see the kinship between the choropleth method and the dasymetric one, though they treat these two as separate forms of cartographic presentation. In yet other sources, e.g. Pietkiewicz, Żmuda (1973), Ratajski (1989), the dasymetric method is treated as one of the kinds of the choropleth map and even the notion of the dasymetric-choropleth map appears. This perspective seems to the present authors to be the most appropriate.

It can be stated that the dasymetric method is equivalent to a kind of a choropleth method, understood as presentation of quantitative data with reference to surfaces and divided into classes with application of logically ordered colours or patterns. The specific feature of the dasymetric choropleth method is that the quantitative data do not refer to the administrative units, but to areas defined independently, namely such within which we assume existence of a certain homogeneity as to the intensity of the phenomenon analysed. These areas are therefore not assumed a priori, but are determined by the author of the map on the basis of the study of the source materials, being the basis for elaboration of a given dasymetric presentation. The dasymetric maps are most often used in 
presentation of just one phenomenon, namely population density. This method, though, can be treated more widely and the dasymetric maps can be used for presentation of other kinds of spatial densities, and perhaps also other types of quantitative data, if we make use of the division of space that differs from the administrative or geometrical one, and the expression of the level of intensity is made through the color or tone scale.

The name of dasymetric map was first used by the Russian Beniamin P. Semyonov-Tian'-Shan'skii. The notion appeared in the title of the map elaborated and published by this author in 1920s, namely: Dazimetricheskaia Karta Europeiskoi Rossii (Dasymetric Map of the European Russia). It was a multisheet map elaborated on the exceptionally detailed scale for this kind of a map, that is: 1:126,000. Its elaboration was based upon the population census of Russia of 1897 . The history of dasymetric maps is, however, much older, for it reaches, according to A.H. Robinson (1982), back to the year 1833, when G.P. Scrope published in his book a not too complicated map of population density of the world. A much better known and based upon more in-depth studies was the map by H.D. Harness (1838), presenting population of Ireland on the scale of 1:633,600, this map having also been commented upon by A.H. Robinson (1955).

The method of presenting population density with the choropleth map based upon the spatial units resulting from the analysis of differentiation of settlement density became quite popular in the second half of 19th century. Dasymetric maps can be found in numerous monographic studies of various geographical regions, containing socio-economic matters, and published in this period. One of the best known analyses of the dasymetric method of presentation of population density is the one by J.K Wright (1936), showing the manner of determination of the units relatively homogeneous with respect to population distribution and, within the framework of these units, determination of population density. Presently, dasymetric maps are quite often encountered in geographical atlases where this type of choropleth map is used for presentation of population density, primarily of rural areas, usually less populated, and is then being complemented with pie diagrams or magnitude signs showing population numbers in greater towns.

The term dasymetric method, and more precisely the adjective dasymetric, is used more commonly only in English and Polish languages. This conclusion can, for instance, be drawn from the analysis of the vocabularies elaborated for the domain of cartography in various countries, as well as from the comparartive analysis of the terms actually used. Such a study was carried out during elaboration of the Multilingual Dictionary of Technical Terms in Cartography (1973), in which individual notions were expressed in 14 languages. The adjective dasymetric was quoted twice in this dictionary, in both cases in the English language, i.e.: dasymetric representation [441.10E, p.114] and dasymetric technique [443.4E, p. 122]. 
In the Russian language, in which the term dazimetricheskaia karta (dasymetric map) was used for the first time, it is now being used virtually solely with reference to the idea of B.P. Semyonov-Tian'-Shan'skii. In the compendia of cartographic methods, elaborated by A.I. Preobrazhenskii (1953) and K.A. Salishtchev (1982) the dasymetric method does not appear at all. Still, in Russian and Soviet cartography one can find numerous maps of population density based upon the units, which are neither administrative nor geometric. O.A. Evteev (1962) refers to such maps as to the smoothed cartograms of enhanced precision (kartogramma utochnennaia sglazhennaia). Certain features of the dasymetric method (in the meaning here adopted) can be found in the technique described by K.A. Salichtchev (1982), who refers to it through the name of the qualitative background method (sposob kolichestvennogo fona).

In the German language the adjective dasymetrisch is also used virtually uniquely in order to refer to the method of B.P. Semyonov-Tian'-Shan'skii. M. Friedrichsen (1924) translated the title of Semonov's map as follows: Die dasymetrische (dichtemessende) Karte des europaeischen Russlands. The only case known to the present authors in which the notion of dasymetric map (dasymetrische Karte) appears in German language in the same meaning as the one used here is the description of this notion in the dictionary of cartographic terms Brockhaus ABC Kartenkunde (1983), put together by W. Stamms. E. Imhof (1962) presents the Dichtekarten (density maps) and distinguishes as one of their groups the relative density maps based upon the "geographical method" (relative Dichtekarten nach der "geographische Methode"). This term must be considered as the most representative German counterpart of the notion of dasymetric map.

Likewise, this term is not adopted generally in the French language, as witnessed by the manner in which it is quoted by $R$. Cuenin (1972), who takes a distance from this notion and assigns the establishment and use of the term dasymetric map to A.H. Robinson.

Italian scholar E. Migliorini (1940) quotes the method of natural regions as one of the methods in which distribution of population can be presented. This interpretation of the method is contained in its meaning which is used in the present report.

In the publication of the Czech specialist Z. Murdych (1983), devoted to the review of the subject-oriented maps, the surface method is mentioned, which is based upon the physico-geographical or economico-geographical units, and which encompasses both quantitative and qualitative presentations. The former can be treated as corresponding to the notion of dasymetric presentation.

The short survey here provided leads to the conclusion that the term of dasymetric method is not internationally accepted, in spite of the fact that the method of presentation referred to through this expression in Polish 
and in English literature is quite frequently applied in many countries, primarily in presentation of population density.

In the classical publications concerning the dasymetric method, which, in particular, present the methods of B.P. Semyonov-Tian'-Shan'skii and J.K.Wright, the statistical data and the topographic map are treated as the basic source materials. The analysis of spatial distribution of population makes it possible then to determine the areas of relatively uniform distribution of population. Such publications mention also the use made of other sources of information on the area, like aerial and satellite photography, land use maps, hydrological, geomorphological, soil, agricultural, mineral resources etc. maps, allowing for the analysis of the utility of natural environment for human colonization. Such analyses, though, especially those based on topographic maps, can only be carried out for the greater scale of presentations. In the cases of lesser scales, in which the dasymetric maps are more often elaborated, especially in geographical atlases, they are frequently put together with the use of other cartographic presentations of the quantitative aspects, which are then appropriately transformed. These cartographic presentations include first of all the dot maps.

In the Methodology of Socio-Economic Cartography of L. Ratajski (1989), similarly as in many other sources, the direct link is indicated existing between the distances among dots and the density (intensity) of the respective phenomenon. The analysis of the density of dots makes it possible to distinguish the areas within which the dots are relatively uniformly distributed, and to determine the density of the phenomenon in these areas according to the formula

$$
D=\frac{W}{d^{2}}
$$

where: $\mathrm{W}$ - weight of a dot,

$\mathrm{d}$ - average distance between dots.

The handbook of L. Ratajski (1989) indicates also that it is possible to apply in the construction of the dasymetric map an interpretation of the dot map constituted by the irregular density network. This kind of a network arises as the result of overlaying of the dot map with a polygonal network in such a manner that each polygon contains exactly one dot. The measure of density of the phenomenon will then be constituted by the surface of the polygon. The dasymetric map is then elaborated in such a way that the values of surfaces of polygons are divided into magnitude classes and all the polygons in respective classes are covered with appropriate colour or pattern, after which the boundaries between polygons belonging to the same classes are liquidated. 
Other methods of use of the dot map in construction of the dasymetric map have been proposed by S. De Geer (1922), G. Enequist (1960) and H. Smeeds (1960).

The dasymetric presentations are sometimes the result of the generalization of the choropleth map based on the administrative units or regular units. This is usually connected with a significant decrease of the scale of presentation - as a rule several times over, in which the initial units (administrative or geometrical) can individually hardly, if at all, be made distinct. In such a situation these units which belong to the same or neighbouring classes are being connected and the resulting pattern of boundaries between fields of various density (the remnants of the initial boundaries of fields) gets importantly simplified.

One can often encounter maps which at a first glance look like the isoline maps, though after a closer look at them it turns out that in some places we deal with the bordering of fields which are not adjacent in the map description (legend). This means that the apparent isoline does not have a well defined value. This concerns, of course, the maps in which the surfaces between the "isolines" are covered with a colour or a pattern. The authors of such presentations wish probably to express an abrupt change of intensity of a phenomenon in definite locations or, otherwise, they are not able to cope with the detailed isoline presentation. If such transformations encompass the dominant part of a map, then the image obtained reminds more the dasymetric than the isoline map. Thus, this kind of procedure can be treated as one of methods of obtaining dasymetric representations. On the other hand, the method of isolines, based upon interpolation, assumes continuity of the "statistical relief", and so the transformations here considered above should be treated as methodologically inconsistent.

Finally, let us mention that one of the sources in depicting the dasymetric maps is constituted by other dasymetric maps, which are either copied or simplified. This kind of procedure, giving in some instances rise to doubts from the point of view of copyright, is quite common, especially in elaboration of atlases.

Thus, we see that the dasymetric maps are frequently the results of transformations applied to various cartographic quantitative presentations. These transformations can sometimes be reduced to enhancement of precision or to generalization of other cartographic presentations (possibly the isolinear ones). Thus, the statement that the dasymetric maps are the result of consideration of the density of phenomena in abstraction from the administrative and census boundaries is not quite correct. The administrative and/or census units are namely oftentimes the basis for the dasymetric image.

The variety of the source materials and the procedures leading to the dasymetric image is presented in the scheme shown below. The basic source materials are constituted here by the maps of the settlement system or of the natural environment, the boundaries of the administrative breakdown, 
as well as statistical data. With the help of these materials it is possible to elaborate the dasymetric map just like this was done by, for instance, B.P. Semyonov-Tian'-Shan'skii and J.K. Wright, but other kinds of maps based upon the quantitative methods can be obtained as well, whose further transformations would lead finally to elaboration of a dasymetric map.

\section{THE SCHEME OF ELABORATION OF A DASYMETRIC MAP}

The basic shortcoming of the dasymetric method is its subjective nature and the lack of uniqueness of the ways and criteria of delimitation of the territorial units. The "zones of uniform density" are an abstract notion and an intellectual shortcut. First of all, no phenomenon appears truly uniformly over space. It can only attain a similar intensity, whose idealized image is presented within the framework of units used in the dasymetric maps. Second, the densities are usually calculated via division of the absolute value by the surface of the unit for which this value had been established.

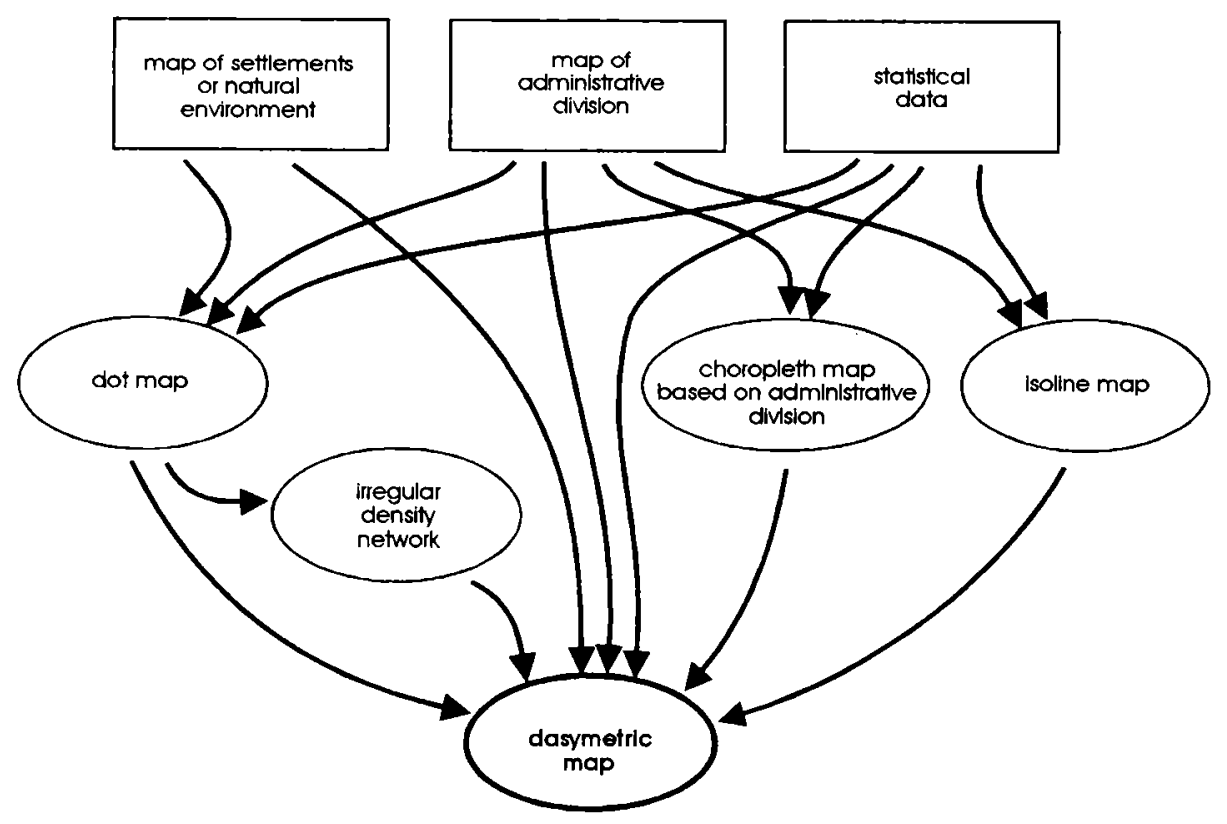

Fig. 1. Different ways to the dasymetric map

Thus, the very definition of density contains the notion of surface for which the given density is determined. Hence, we should talk of the similarity of density levels in various units rather than of the fields of equal density. Still, the term mentioned is being used to designate the areas within which the objects (events) are distributed relatively uniformly in space. 
The methods of delimitation of the basic fields are in the case of a dasymetric map different and so they can lead to determination of different ultimate images. This sometimes gives rise to doubts as to the reliability of the presentation. Note, though, that one can hardly speak of the truth or reliability of presentation in the case of presentation of such an abstract entity as - in this case - density.

Another weak point of the method is the fact that the values presented are approximate, the output of a compilation. While in the case of a choropleth map based upon the administrative units we deal with assignment of relatively precise values, often taken from the censuses, to the respective fields, in the case of a dasymetric map we are often forced to perform estimation of density, which leads, in a natural manner, to appearance of imprecisions. That is why in terms of statistical cartometricity we can speak of a certain imperfection of the dasymetric maps.

The dasymetric presentations are often based upon various kinds of data, transformed in a variety of manners and brought to a relatively uniform image, so that a reader of the map can hardly realize in what way have they been elaborated. This concerns in particular the small scale maps, in which various source materials are being used, coming from different countries and sometimes also from different time periods. This leads, as well, to a certain methodological lack of clarity of this form of presentation.

We can also mention here the relatively low utility of the dasymetric maps in the comparative analyses, such as the study of correlation of phenomena or their dynamics over time. This is the direct consequence of the fact that the territorial breakdown which is adopted in this approach is not the universal, the widely used one, but proper for just one concrete event, and even this only in a definite period of time.

Finally, the shortcomings of the dasymetric maps include the laboriousness of their elaboration. This results oftentimes from the necessity of planimetric asessment of the surfaces of the units distinguished, usually involving strenuous analyses, and frequently quite complicated calculations.

The above mentioned weak points of the dasymetric maps can be confronted with their positive features, and it can often happen that the characteristics thus controversially assessed will be the very same, but evaluated from a different angle.

When elaborating the dasymetric map we abstract - at least partly from the administrative units adopted in the classical choropleth map. This is indeed especially advantageous when such units are highly differentiated as to their shape and magnitude. Besides this, within the confines of the administrative units population density is very often differentiated, and the choropleth presentation ignores this differentiation, and therefore we obtain an essentially flattened, and therefore deformed image of the "statistical relief". The response to this negative feature of the choropleth maps 
based upon the administrative units is exactly constituted by the application of the dasymetric method. The opponents of the presentations elaborated with this method might at this point indicate that we dispose of the method of presentation of the statistical data accounting for the internal differentiation of the census units, namely in the form of the dot maps. These maps have this advantage over the choropleth maps that they allow to avoid the frequently cumbersome territorial delimitation and direct presentation of densities. And in fact, the dot method is the most serious competitor of the dasymetric method in presentation of statistical information accounting for the spatial differentiation of the intensity of phenomena which have little correlation with the administrative breakdown. While, however, in the case of use of the single weight dots and preservation of the rigour of countability, and given high degree of differentiation of the intensity of a phenomenon, the regions with strong intensity can be clearly distinguished, such a discrimination of the regions with low and very low intensity is quite difficult, since one dot, which has to be located in one definite place, represents the magnitude of the phenomenon over the whole area represented. Similarly, it is difficult in such a case to represent the link between, say, population, and the elements of the environment, like, for instance, a river valley. Further, it can be stated that the dasymetric maps are more resistant to the generalizations resulting from the shrinking of the scale of presentation, since it is not necessary in the case of these maps to increase the weight of a dot, which sometimes dramatically changes the image of distribution of the phenomenon. E. Imhof (1962) writes that "the relative maps of density based upon the geographic (i.e. dasymetric) method are superior - first of all in the small scales - with respect to the graphical clarity of presentation, to the dot maps, because instead of the images, recalling the sand heaps, which are often hard to evaluate, we obtain here a clear, unique division of surface with easily read out relative values". It appears that the authors of geographical atlases around the world are of similar opinion, because the dasymetric method belongs to the most often applied ways of showing population density and is effectively replacing the dot method.

The dasymetric method is treated by some geographers and cartographers as better than the isoline method in presentation of such phenomena as population density. This opinion is justified by the fact that the dasymetric method assumes spatial continuity of the variability of a phenomenon's intensity, while population density is characterized by locations of abrupt changes, being usually the boundaries (barriers) of definite environmental conditions. The dasymetric map allows to distinguish such locations (lines), though this takes place at the expense of the graphical legibility of the image (the "statistical relief" becomes more difficult to imagine).

The consciousness of ambiguity in the determination of boundaries of the units makes the room for a certain freedom in delimitation of the 
fields, which allows for paying more attention to the characteristic features of the spatial differentiation of population density (or other phenomenon) by making of a reference to the orographic, hydrological, agricultural and the like divisions. While a choropleth map which is based upon the administrative units and is unique in its construction both with respect to the course of units' boundaries and to the respective statistical values becomes often the subject of analyses only after it has been elaborated (the author of a choropleth map does not necessarily have to display the knowledge of geography), in the case of a dasymetric map the phenomenon represented is subject to analysis during elaboration of the map. During creation of a map one is therefore forced to consider in depth the matters to be shown, since such a map can convey the suggestion as to the causes and perhaps also as to the consequences of the spatial distribution of the given phenomenon. Thereby a certain didactic value of the dasymetric presentations is unveiled, although connected with simultaneous establishment of the room for abuses and imposed interpretation.

Thus, we can see that the controversies connected with various kinds of quantitative presentations result primarily from the difficulty in simultaneous satisfaction of the requirement of precision and intuitive appeal of the methods. Let us remind here yet of the stipulation that the method of presentation be selected so as to match appropriately the nature of the phenomenon shown in the map.

\section{REFERENCES}

Brockhaus ABC Kartenkunde, 1983, VEB F.A.Brockhaus Verlag, Leipzig.

Cuenin R., 1972, Cartographie générale, Collection Scientifique de l'Institut Géographique National, Editions Eyrolles, Paris.

De Geer S., 1922, A map of distribution of population in Sweden: method of preparation and general results, Geographical Review, 12, 1, 72-83.

Enequist G., 1960, A method for mapping density, Norsk Geografisk Tidsskrift, 17, 271-277.

Evteev O.A., 1962, Karty naseleniya v sovetskikh kartograficheskikh izdaniyakh i geograficheskoi literatur'e za 20 l'et (1940-1960), Voprosy Geografii. Kartografiya, 56, 209-228.

Friedrichsen M., 1924, Die dasymetrische (dichtemessende) Karte des Europaeischen Russlands, Petermanns Geographische Mitteilungen, 70, 214-215.

I m h of E., 1962, Thematische Kartographie, Beitrage zu Ihrer Methode, Die Erde, 93.

Migliorini E., 1940, Note metodiche sui sistemi usati per rappresentare la distribuzione della populazione, Bolletino della Reale Societa Geografica Italiana, $53,262-274$.

Multilingual Dictionary of Technical Terms in Cartography, 1973, Franz Steiner Verlag, Wiesbaden.

Murd y ch Z., 1983, Tematicka kartografie (Thematic Cartography, in Czech). Charles University in Prague, Faculty of Natural Sciences, Statni Pedagogicke Nakladatelstvi, Praha.

Pietkiew i cz S., $\dot{Z}$ m u d a S., 1973, Stownik pojęc geograficznych (Dictionary of Geographical Notions, in Polish), Wiedza Powszechna, Warszawa. 
Preobrazhenskii A.Y., 1953, Ekonomicheskaia kartografiya (Economic cartography; in Russian), Gosudarstvennoie uchebno- pedagogicheskoie izdatel'stvo Ministerstva Prosveshcheniya RSFSR, Moskva.

Rat ajski L., 1973, Metodyka kartografii spoteczno-gospodarczej (Methodology of socio-economic cartography, in Polish). Ist Edition, PPWK, Warszawa.

Ratajski L., 1989, Metodyka kartografii spoteczno-gospodarczej (Methodology of socio-economic cartography, in Polish), IInd Edition, PPWK, Warszawa.

Robins on A.H., 1955, The 1837 maps of Henry Drury Harness, Geographical Journal, 121, 440-450.

Robinson A.H., S al e R., Morris on J., 1978, Elements of Cartography, IVth Edition, John Wiley and Sons, New York (Ist Ed.: 1953).

Robinson A.H., Sale R., Morrison J., Muehrcke P., 1985, Elements of Cartography, Vth Edition, John Wiley and Sons, New York.

Robins on A.H., 1982, Early Thematic Mapping in the History of Cartography, The University of Chicago Press. Chicago \& London.

Salis h tchev K.A., 1982, Kartovedeniye (Cartography, in Russian), 2nd Edition, Izdatel'stvo Moskovskogo Universiteta, Moskva (Ist Ed.: 1974).

Scrope G.P., 1833, Principles of Political Economy Deducted from the Natural Laws of Social Welfare, and Applied to the Present State of Britain, Longmans, London.

Smeeds H., 1960, A method of constructing density choropleths on dot maps of population, Abstracts of Papers, International Geographical Congress, Norden, 266-267.

Wrich $t$ A.I., 1936, A method of mapping densities of population with Cape Cod as an example, Geographical Review, 26, 103-110. 